\section{Clarifying the position statements of the Centrall Drug Authority Executive Committee}

It is remarkable that Dr Scott begins his response ${ }^{[1]}$ to our rebuttal ${ }^{[2]}$ of his earlier editorial ${ }^{[3]}$ by stating that his paper 'tries to avoid covering all the arguments put forward' by us. Indeed, our impression is that he has merely repeated the position in the earlier editorial, that he uses rhetorical devices to distort our views, and that he ignores the key points we have made.

First, Dr Scott repeats his statement that our position statement suffers from confirmatory bias, and fails to address the evidence base on harms and benefits of drugs that we cite. He distorts our views by drawing an analogy between our citations of this evidence base and past misconceptions about antiretrovirals. We think that other clinicians will agree that the point made in our rebuttal - that substances are associated with well-researched harms, as well as with potential benefits - cannot simply be ignored.

Second, Dr Scott again laments the various United Nations (UN) conventions, and the harms associated with current drug laws. He distorts our views by accusing us of supporting the UN conventions and failing to recognise harms associated with current drug laws. However, as we stated in our rebuttal, the intention of our position statements is precisely to bring attention to and advocate for harm reduction, both with respect to cannabis and more generally, as a key public health approach to addressing tobacco, alcohol and other substance use.

Third, Dr Scott again draws a stark contrast between prohibition and legal regulation, criticising decriminalisation as merely a form of prohibition. He distorts our views by assuming that we stand wholly for prohibition. In our rebuttal we emphasised that a broad range of regulatory options lie between decriminalisation and commercialisation, noting that decriminalisation is merely one practical step in the right direction. The evidence indicates that 'Big Cannabis' is not an imaginary construct that can simply be ignored.

Nevertheless, we would note, as we did in our earlier rebuttal, some overlap between our position and Dr Scott's. We seem to agree on a public health approach to the regulation of tobacco, alcohol and other substances, on a focus on harm reduction rather than a 'war on drugs', and on the recognition that alcohol is the most widely used and harmful substance in the South African context and so deserving of particularly careful regulation. We hope that many clinicians, as well as members of the public, will also find common ground on these issues.

\section{Dan J Stein}

Department of Psychiatry and Mental Health, Faculty of Health Sciences, University of Cape Town, South Africa

dan.stein@uct.ac.za

\section{Eva Manyedi}

School of Nursing, Faculty of Agriculture, Science and Technology, North-West University, Mahikeng, South Africa

For the Executive Committee of the Central Drug Authority (Carol du Toit, Dan Stein, David Bayever, Eva Manyedi, Johlene Ntwana, Lethiwe Ndlovu, Mogotsi Kalaemodimo, Moses Gama, Pelmos Mashabela, Peter Ucko)

1. Scott K. Adding to the cannabis debate: Comment on various Central Drug Authority papers. S Af Med J 2016;106(9):838-839. DOI:10.7196/SAMJ.2016.v106i9.11270

2. Stein D, Manyedi E, for the Executive Committee of the Central Drug Authority. Position statement on cannabis: A step forwards. S Afr Med J 2016;106(9):837.DOI:10.7196/SAMJ.2016.v106i9.11222 3. Scott K. Comment on the Central Drug Authority's position statement on cannabis. S Afr Med 2016;106(6):545-546. DOI:10.7196/SAMJ.2016.v106i6.11036

S Afr Med J 2016;106(9):840. DOI:10.7196/SAMJ.2016.v106i9.11283 